\title{
(Sin: \\ ISCAR 2017

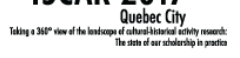 \\ Development of constructive response to frustration in adolescence using arts-based approaches
}

Elena Yangicher

PhD in Educational Psychology

Moscow State University of Psychology \& Education

Moscow, Russia
YANGICHER.L@GMAIL.COM

\begin{abstract}
The article focuses on the problem of the emotional development constructive response in adolescence, which is of increasing relevance within the context of the rise in negative social manifestations, changes in social situation of development. The aim of this research is to formulate a constructive response model's development to adolescent frustration from socially advantaged and disadvantaged groups using art-based approaches (specifically art therapy) combined with traditional psychological tests and modeling experiments.

The study draws on the concepts of L.S. Vygotsky about the peculiarities of adolescents' mental development and the role of this period in the formation of personality, as well as various aspects of affect and needs development in childhood (L. I. Bozhovich). The study considers the position of mental states as a particular psychological category and their (states) integrating function, conception of the regulation of mental states (N. D. Levitov), theoretical and experimental development for the diagnosis, management, and directed formation of the mental states (Yu. B. Nekrasova) as well as the concept of experiencing ("perezhivanie") as described by F. E. Vasilyuk.

A range of methods, combining quantitative and qualitative approaches were used in the study: video observation (outlined in the protocols); mathematical statistics; tests and modeling experiments. Experimental studies were carried out over a duration of five years within three different types of schools in the region of Moscow $(n=203$, aged 13-15). One conclusion of the experimental studies, the author's program was implemented in a number of educational institutions in Moscow and other regions in Russia.
\end{abstract}

Keywords : Reactions to frustration; Adolescents; Psychological and emotional regulation; Mental states; Positive emotional response; Perezhivanie; Self-regulation; Arts-based approaches; Art therapy. 


\section{Introduction}

Today, the problem of psychological and emotional regulation of a personality in difficult situations becomes evident. The need for psychological support is especially acute for adolescents from socially disadvantaged groups. Analysis of the studies in this area revealed that methods of psychological influence with positive effect on stable stereotypic reactions of adolescents to frustration remain underdeveloped. In defining frustration as a specific mental state that evolves under special conditions, we rely on methodological statements in Russian psychology about mental states, their regulation and directed formation (Levitov, 1967; Nekrasova, 1994; Prohorov, 1990; Vasiljuk, 1984). Such approach opens the door for developing positive emotional reactions to frustration with the help of special means. In this context, we view special means of art therapy as instruments of directed formation of positive mental states and reactions, and self-regulation skills. At the same time, our main focus remains on studying frustration in the context of psychological and emotional functioning of a personality and on regulation of negative states in the process targeted influence. This article is an attempt to analyze some aspects and results of the psychological correction program using the experimental method of Vygotsky $(1966,1998)$. The article describes the study that refers to theoretical and methodological statements of the Moscow psychological school based on the cultural-historical theory of L. S. Vygotsky that can be used for conducting researches in the tradition of this scientific school.

\section{Defining Frustration as a Psychological Phenomenon}

Frustration is a complex phenomenon. It has significant differences in definition in psychology. There are a number of key characteristics that differentiate frustration from other related categories of states - conflict, stress, concern, deprivation, etc., for example, the situation must include social influence on a personality and have a certain time characteristic (short time period) (Levitov, 1967; Lukin, 1993; Rosenzweig, 1944; Tarabrina, 1984). Also, important reasons for such phenomenon are internal conflict that gives rise to this state, and unsurmountable (in the subject's opinion) barriers on the way to the goal, caused by both internal and external factors.

Psychology developed a number of theories of frustration, such as a theory of frustration fixation (Freud, 1923), a theory of frustration regression (Barker, Dembo, \& Lewin, 1943), a frustration-aggression theory (Dollard, Miller, Doob, Mowrer, \& Sears, 1939), "heuristic" theory of frustration (Rosenzweig, 1944). All these concepts reveal controversy between views on the causes and effects of frustration, and diversity of understanding of this phenomenon.

In Russian psychology, the issue of frustration was first raised in the work of Levitov (1964b) who defined this phenomenon as a mental state. According to this statement, frustration is a human mental state caused by unsurmountable barriers on the way to one's goal and reflected in typical feelings and behavior. Such position is a special interest 
for researchers in the context of development and formation of constructive reactions to frustration during positive changes in emotional states and reactions.

School psychologists and teachers often have to deal in their work with high frustration among children triggered by hurdles that affect personality development and fix inadequate reactions to frustration. Psychological assistance to adolescents has to aim at prevention and correction of nonconstructive ways of overcoming frustration. Most psychologists say that adolescence is the most difficult age period in emotional development of a personality (Bozhovic, 1968; Kon, 1989; Prihozhan, 2000; Rean, 1999). This age group is particularly sensitive towards external influences, that's why it is essential to create supportive social situation of development (Vygotsky, 1991, 1998) using special methods, and this may become a determining factor in the positive context of further personality development. Undergoing through internal conflicts with oneself, and with others has been called a common psychological characteristic of this age group, when an adolescent realizes himself/herself as a personality. L. S. Vygotsky notes a typical change in interests (dominants) of an adolescent. Russian authors point to the restructuring of established needs and the birth of new ones associated with the solution of internal conflicts and "change in types of activity" (Bozhovic, 1968; Leont'ev, 1971; Vygotsky, 1998). Due to high emotional vulnerability inherent in adolescence, this age group tends to have inadequate reactions that trigger abnormal behavior. Adolescents cannot control themselves because they are not acquainted with self-regulation tools. Hence, a special need for timely psychological correction arises.

In our study, we take as a basis the concept of frustration developed in Russian psychology (Levitov, 1967; Prohorov, 1990; Vasiljuk, 1984), according to which frustration is a mental state that develops in a situation of strong motivation to achieve a goal, find a solution, satisfy an important need, and the existence of obstacles to such achievement, and is manifested in typical concerns and behavior. Reaction to frustration is the response of an individual to insurmountable (objective or subjective) barriers that block the way to his/her goal, and it is accompanies by a wide spectrum of emotions (Krech \& Livson, 1969; Levitov, 1967; Rosenzweig, 1944; Tarabrina, 1984; Vasiljuk, 1984).

We divide adolescents' reactions to frustration into constructive and non-constructive. Constructive reactions to frustration are characterized by adequate and active behavior, awareness of the situation, and focus on finding solution depending on the subject's capabilities. Nonconstructive reactions are manifested in denial of an adequate solution, recourse to self-defense reactions, focusing on the obstacle, emphasizing the guilt, and accusation of others.

Development of constructive reactions to frustration is driven by: regulation of the emotional state; selection of efficient strategies of reaction; resilience to effects of difficult situations; individual and typological characteristics of a personality; specific needs and motives; mechanisms of volitional regulation (Levitov, 1964a, 1964b, 1967; Rosenzweig, 1944, 1945; Vasiljuk, 1984, 1991). The above factors contributing to develop resilience of an adolescent and frustration mean potential positive changes in reactions to frustration. So, provided a targeted influence is applied. 
Our study is based on the theory of frustration as a mental state, which makes it possible to study reactions to frustration only, when by frustration, it meets everything that the source of frustration provokes, including the mental state, and this became the strategic idea of our experiment. The methodology for studying frustration was first developed by Rosenzweig $(1945,1976)$ who found main types and directions of reactions to frustration. For adolescents, we developed our own classification and singled out indications of constructive and non-constructive reactions to frustration in this age period.

Psychological characteristics of constructive reactions of adolescents to frustration are: 1) optimal intensity of frustration; 2) neutral reactions of necessary stubborn, ego defensive and obstructive dominant types; 3 ) reactions directed at oneself of a necessary stubborn type; 4) positive mental states as a background for reaction: calm, prudence, openness.

Psychological characteristics of non- constructive reactions of adolescents are: 1) high intensity of frustration; 2) reactions directed at surrounding environment - by the type of emphasis on the situation, fixation on obstacles, denial of one's guilt and accusation of others, insistent demand that another person find the solution; 3) reactions directed at oneself - by the type of self-accusation, by ego defensive type with self- justification and reference to circumstances; 4) negative mental states as a background for reaction: anger, annoyance, aggressiveness.

By defining reaction to frustration and its manifestation intensity as a stereotypic reaction, we assume that manifesting frustration is a norm and inherent to all humans having positive influence on social adaptation. At the same time, the high level of frustration leads to formation of negative personality traits in adolescents, as well as too low level. That's why, it is necessary to develop constructive ways of overcoming frustration in adolescence using special means and methods, which became the primary objective of our study.

\section{Theoretical and Methodological Basis}

The study draws on the concepts of L.S. Vygotsky about the peculiarities of adolescents' mental development and the role of this period in the formation of personality, as well as various aspects of the development of affect and needs in childhood (Bozhovic, 1968). The study considers the position of mental states as a particular psychological category (Levitov, 1964a, 1964b) and their (states) integrating function, the conception of the regulation of mental states (Prohorov, 1994, 2002); theoretical and experimental development for the diagnosis, management, and directed formation of the mental states (Nekrasova, 1994); classification of reactions to frustration (Levitov, 1967; Rosenzweig, 1945); the theses about using art therapy in development of positive emotional reactions of a personality as well as in self-expression and self-realization in the art products (Kramer, 1975; Malchiodi, 2003; Naumburg, 1973); the concept of experiencing ("perezhivanie") as described by Vasilyuk (1984). 
Seeing frustration as a mental state makes it possible to change reactions to frustration by regulating these states. The issue of development and preservation of constructive reactions via mechanisms of mental state regulation becomes increasingly urgent in light of several studies that confirmed the change in and even break of stable personality traits under the influence of mental states driven by difficult relations, critical situations and labor activity. It has been proved that recurrent frustration gives rise to new negative stable personality traits (Kuzmina \& Yakunin, 1997).

Mental states are characterized by post-situational reproductibility (like conditioned reflex) and, if relevant and recurrent, can transform into stable personality traits (Kulikov, 1997; Levitov, 1964a, 1964b, 1969; Prohorov, 1990, 1994, 2002; Sosnovikova, 1972). In childhood, a personality is a combination of different fragmentary mental states, and only through work, learning and experience an integration of separate states into personality traits takes place (Levitov, 1969). Character dynamics - acquisition, change, or liquidation - goes through the transitional phase of the mental state. Due to the transitional position of the mental state there is a need to look for methods, means and conditions in order to translate productive states into personality traits (Levitov, 1969; Nekrasova, 1994).

Both character and mental state are difficult to simulate without support on previously analyzed information about human being: there are no identical characters, as there are no identical mental states. However, the changing process may differ - a mental state translates into a personality trait only after its preservation. In some cases, the process is slow (repeated preservation is required), in others - rather quick (Levitov, 1969).

Frustration, like all mental states, can be temporary, transient or typical for human nature. A situation is the trigger for both positive and negative states (Prohorov, 1990, 1994). The situation of frustration works in the same way. The process of living through a situation involves mental states that exist in "actual time period". These states bind processes and personality traits, ensuring adequate response to the situation thanks to its integrating function (Prohorov, 1994). The ongoing time period linked to the person's social functions lasts from hours to days and has an integrating function that forms a personality psychological system.

In longer time periods (a month/a year and longer) mental states regulating mental processes lead to development of stable personality traits, character, and influence the behavior, including the response to frustration. The adolescents tend to have mono states with a large emotional component. By duration, such states are largely either actual (seconds/minutes) or ongoing (hours/days) (Prohorov, 1990; Prokhorova, 1996). Thus, arises the need to look for means of actualization, fixation and development of positive mental states among adolescents.

Our research is aimed at studying frustration through the psychological and emotional functioning of a personality. In this context, the process of mental state regulation, reflected in full in system and function model of Prohorov (2002), draws special interest. One of the most important experimental studies is the work by Nekrasova (1994) on diagnostics, control and directed formation of mental states during social rehabilitation of a personality. 
The regulation structure for mental states builds up in the process of life activity, learning, overcoming situations, adaptation to surrounding conditions. Such structure has an integrating function, hence helps organize mental processes. Mental states provide background for mental processes. Mental states and personality traits are interrelated: all traits are involved in the actualization of states that facilitate integration of traits in functional structure. The process of mental state self-regulation is based on integrating function, which provides for the unity of three: traits, state and process (Prohorov, 1994, 2002).

At the level of single state (single mental act) self-regulation is ensured by using particular methods. For example, transition from one state to another (from anger to calm, etc.). Using relevant methods actualizes other state, and thanks to integrating function, a new psychological structure unfolds (processes - actual state - trait). This leads to change in the mental state image that is reflected in new activity, increase in productivity of mental processes, intensity of physiological reactions, etc., and is felt, reflected, and described by the subject differently than in underlying state (Prohorov, 2002). Based on the system and function model of A.O. Prokhorov, the model of single mental state regulation may look like in the Figure 1 below.

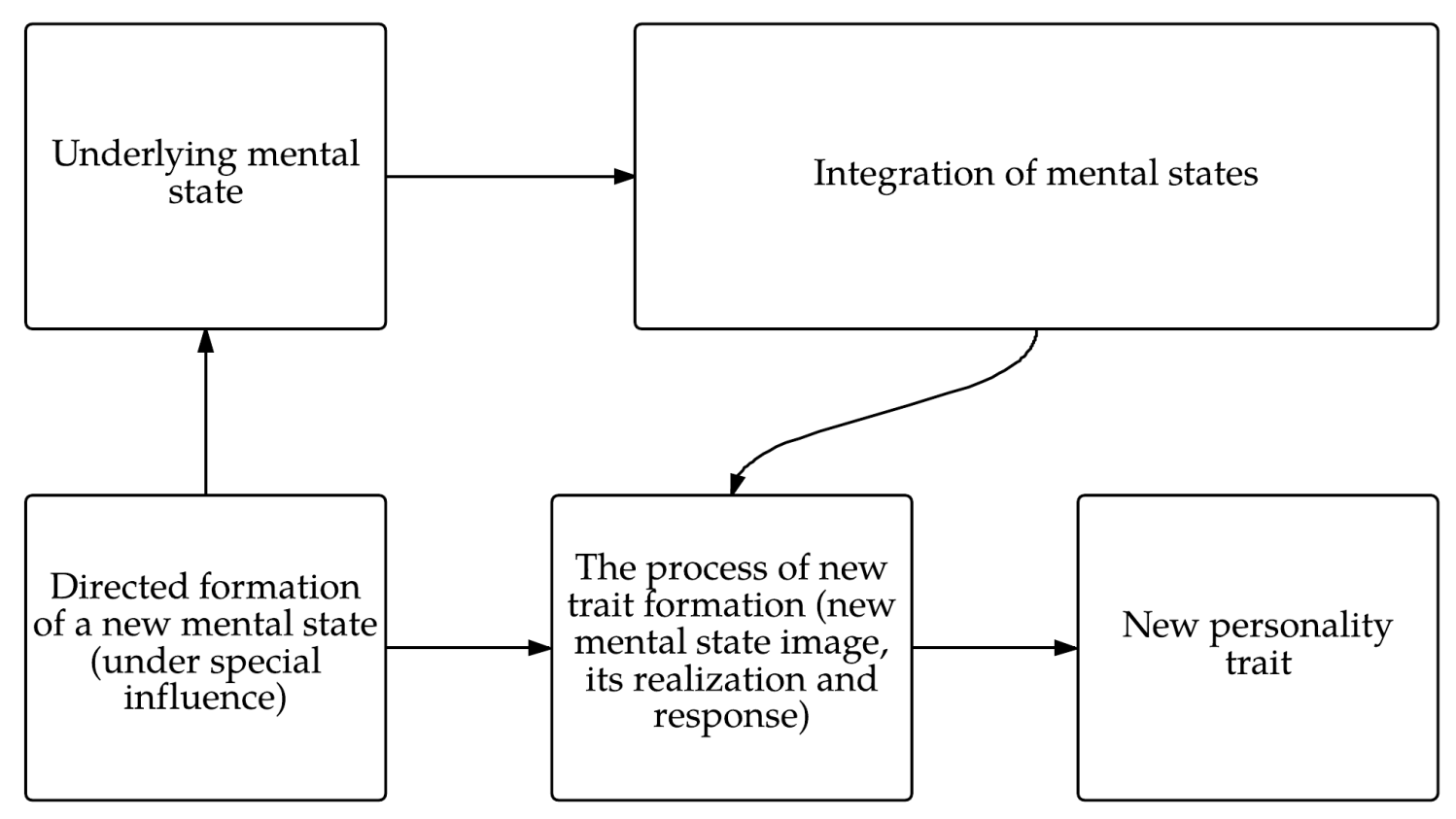

Figure 1. The model of single mental state regulation

The above model clearly demonstrates the importance of directed influence on mental state and its correlation with the process of new trait formation. Our study considers the directed influence approach to mental states (in particular, frustration) in order to develop constructive responses and new reactions (restructuring of existing stereotypes). 
In his system and function model of mental state regulation A.O. Prokhorov describes mechanisms outlined by different authors. The basis of this process lies in the integrating function of the mental state that can be attributed to the mechanisms of mental regulation (Prohorov, 1994). The other components of the regulatory process are the image of actual state and the degree of awareness, the completeness and adequacy of this image. The mental image relates not only to activity, but also to system organization of human consciousness (Smirnov, 1981). It is the mental image that presents system of levels at which a person reflects his/her state as objective reality, and displays "an internal picture of actions" on state self-regulation (Dikaya \& Semikin, 1984). In certain circumstances, the reflection of interoceptive signals coming out of the internal environment with the potential of becoming conscious may take place. Adam (1998) experimentally proved the existence of conscious "visceral perception", i.e. getting visceral information via verbal communication.

Thus, it is possible that under directed influence a new state image can be formed (based on almost unconscious feelings and perception at psychophysiological level). By using certain methods, a transition from one state to another at different levels of consciousness takes place. It is the "new" state that unfolds the process-traits-functions structure (Prohorov, 2002). One of the main mechanisms of self-regulation processes is a response that triggers not only mental regulation of individual processes (for example, biological response), but also of the entire mental state.

Another mechanism of self-regulation processes is reflection. According to a number of researchers, it is a universal mechanism of self-regulation process that "fixes" the activity process and enables conscious influence on this process. Reflection correlates with the highest forms of volitional behavior as realization of a life plan and with the highest forms of emotional experience, which results in "creative transformation" of oneself and one's own life (Vasilyuk, 1984). As a mechanism ensuring effectiveness of self-regulation, the subject's motivation can also be used (Prohorov, 2002).

To sum up, regulation of mental states is done with the help of integrating function of mental states, actual state image (degree of awareness, level of completeness and adequacy of the state), response, reflection, and motivation of the subject. The principle of mental state self-regulation is the foundation of formation of new traits. Under the directed influence the process of formation and fixation of states in stable traits accelerates significantly.

In the experimental part of our study the development of constructive reaction to frustration was considered through the prism of actual and ongoing time periods: actualization of situational states (sec./min.) and longer states (1-1.5h) that contribute to integration of mental states into the process of mental state formation. For targeted formation of positive (constructive) states, a number of methods, including means of art psychology, are used. One of the key therapeutic mechanisms of art influence on personality has been thoroughly considered by Vygotsky (1972) in "The Psychology of Art", detailing the phenomenon of the aesthetic response and cathartic experience, during which the power of passion is brought to a state of complete discharge, followed by a calming, purification (processed and purified). The esthetic catharsis lies in self-destruction of affects, their explosive reaction that 
triggers the discharge of the accumulated emotions (Vygotsky, 1972). From the perspective of mechanisms of mental state self-regulation developed in Russian psychology by Kulikov (1997); Prohorov (1994, 2002) and others, art means, to our opinion, can be viewed as an instrument to form and fix positive states transforming into stable personality traits.

Art therapy has its characteristic features that differentiate it from other methods: selfexpression (non-verbal communication channel, visual, plastic and audial expression), metaphoricalness, art and creativity (self-expression and self-realization in art products). During the "constructive art process" kids feel freedom of self-expression. Contact with art material integrates all feelings, strengthening one's "self", what is especially important for adolescents. The exclusive characteristic of this method is triadity, "three voices" of art therapy: an artistic image, a subject, and a specialist (Dalley, Rifkind, \& Terry, 1993). It is resource-intensive as it lies beyond the subject's daily experience. The created artistic images help to express emotions at symbol level, realize and verbalize them.

Foreign researchers of modern times (Essex, Frostig, \& Hertz, 1996; Moriya, 2000; Riley, 2004) believe that art therapy is the most appropriate way to work with adolescents, with the most successful long- term psychological correction implemented at schools. Art is a natural sensor mode of expression for humans, as it involves physical contact, smelling, and other senses within the sensor experience of a person, with drawing and other art activities mobilizing sensor memory like no verbal expression or interference can mobilize (Malchiodi, 2003; Steele \& Raider, 2001). Art therapy process triggers catharsis of esthetic reaction, during which an adolescent defines negative poles of emotions, responses to them and then dispose of them. It was noted, that children from dysfunctional families become calmer during art process and experience "hypnotic state" (Malchiodi, 2003).

Based on the definition of frustration as a mental state it is possible to look at correction of negative reactions from the perspective of mental state regulation by directed influence on them with the help of special means. This position became the basis of theoretical model of the research. The author refers to the assumptions of Russian psychologists about integrating and regulating functions of mental states (Kulikov, 1997; Levitov, 1964a, 1964b, 1969; Prohorov, 1994, 2002; Sosnovikova, 1972), meaning that positive states and reactions can be fixed in personality traits of an adolescent, if special influence is applied (Levitov, 1969; Nekrasova, 1994). Some of important features of mental states are dynamism and postsituational reproducibility (Nekrasova, 1994; Prohorov, 1994). Therefore, the correction process is viewed as a natural psychological and pedagogical experiment, which actualizes certain mental states leading to positive changes.

\section{Theoretical Model}

The comparative analysis of the above-mentioned theoretical statements helped develop a proprietary theoretical research model (Fig. 2) and to outline main psychological factors that determine evolution of constructive reaction of adolescents to frustration (under di- 
rected influence by means of art therapy). The resulted theoretical model became the basis for the experimental part of the study.

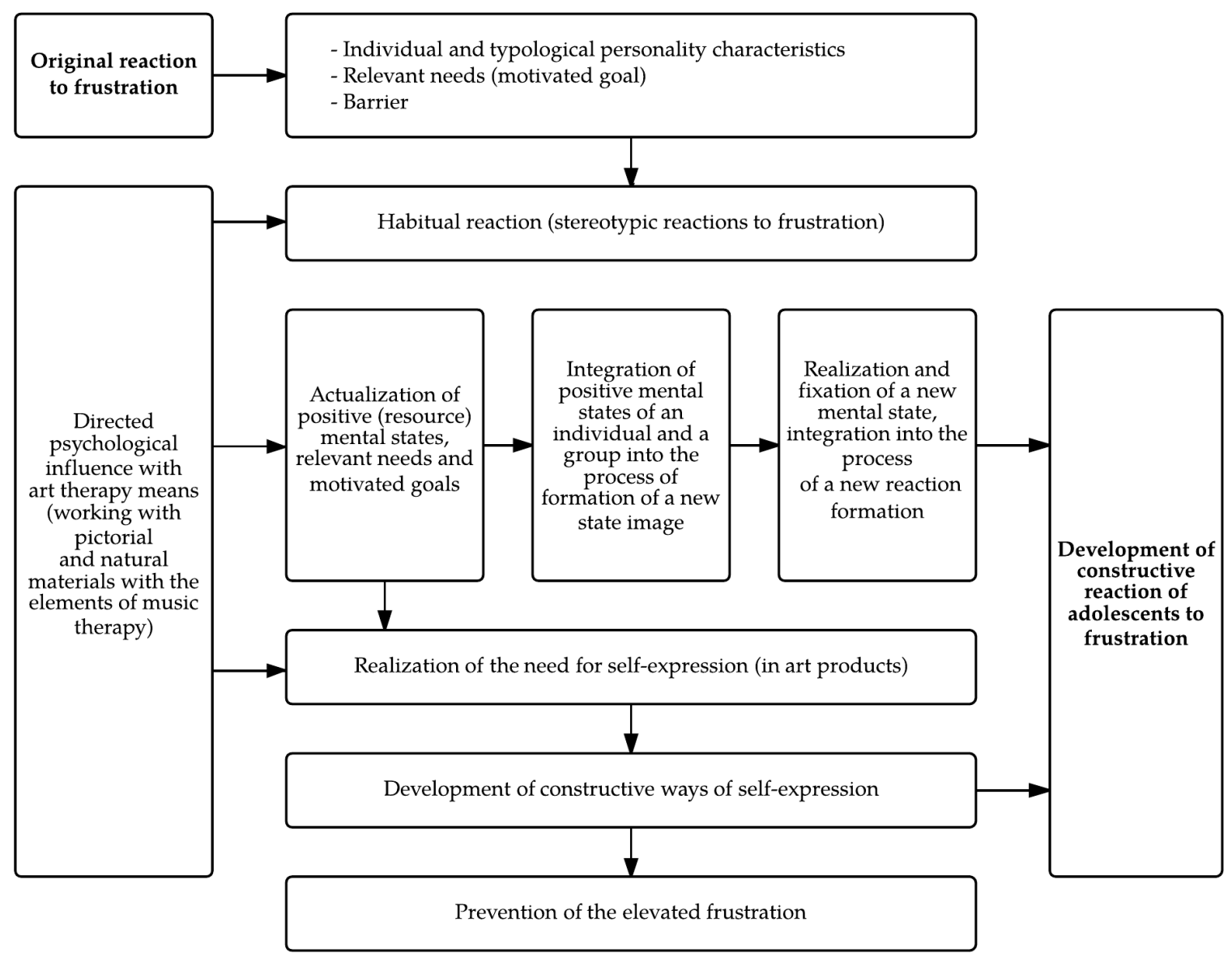

Figure 2. Theoretical model of development of adolescents' constructive reactions to frustration by means of art therapy

The outlined factors drive changes in stereotypes of emotional (in a state of frustration) reactions and have the following characteristics: 1 ) emotional regulation of reactions during directed formation of mental states: integration of positive states into the process of formation of personality traits (transition from one state to another, tendency to changes in negative states and reactions and replacement of them with positive ones, and, as a result, restructuring and fixation of the reaction); 2) mental regulation of the entire mental state: building of the state image at different levels of consciousness (conscious and unconscious), realization of the state during the feedback phase and, thus, fixation of the constructive reaction; 3) realization of need for self-expression and, consequently, prevention of elevated frustration.

The outlined psychological factors determining the evolution of constructive reactions of adolescents to frustration are based on the theory of frustration as a mental state (Levitov, 1967), system and functional model of mental state regulation (Prohorov, 2002), ex- 
perimental works on management and targeted formation of mental states (Nekrasova, 1994), theoretical statements of the art therapy classics, Kramer (1975); Naumburg (1973) and others.

Under the directed psychological influence on a stable stereotypic reaction and its typical manifestations with art therapy means, the hierarchy of components of the reaction to frustration shifts towards a more constructive one, and a positive change in frustration intensity is recorded. The directed psychological influence includes: constructive overcoming of simulated barriers during the art therapy process, directed formation of positive emotional states to be fixed further as personality traits through engagement with pictorial and natural materials (with the elements of music therapy).

The formation of a new reaction implies: actualization of positive mental states, creation of a new state image (awareness degree, its completeness and adequacy, feedback). The integration of positive mental states into the process of a new reaction formation includes the tendency to changes in, fixation and replacement of negative states with positive (constructive) ones.

The change in the negative reaction stereotype occurs during fixation of positive mental states, regulation and restructuring of the reaction during the art therapy process based on the creativity potential of the subject. Specially organized creative activities stimulate self-expression and self- realization of adolescents in art products becoming the factor that prevents and reduces elevated frustration. Art therapy process encourages catharsis of esthetic reaction as relevant feelings and states are given response.

Created visual images serve to help adolescents to work through their desirable projections and past experience in the course of changing these images (on a physical level). Fixation of the constructive reaction is ensured by the awareness of the new state image through activation of sensory channels when using combination of special art therapy means: pictorial and natural materials with music elements (visual, kinesthetic and audial channels are involved). The tendency towards fixation is secured by verbal response (repeat of the positive part of the process) and reflection. The format of the exercises (thematic art therapy group) contributes to fixation of a new positive experience (adolescents watch, listen, and cooperate, facilitating feedback in the group). Theoretical modeling of the development process for adolescents' constructive response to frustration by means of art therapy became the basis for the experimental part of the study.

\section{Objectives and Methods of the Study}

The study used a combination of methods with both quantitative and qualitative approaches: observation; video observation (outlined in the protocols); methods of mathematical statistics (one- way analysis of variance, Student's t-test, Chi-square test); ascertaining and modeling experiments (development and implementation of a special art therapy program that includes author's methodology "Floristic collage"). The work used diagnos- 
tic methodologies: methodology of studying reactions to frustration by Rosenzweig (1945) that defines types and directions of reactions; verbal frustration test by L. Sobchik (for adolescents) that reveals the intensity of frustration; modified matrix for defining consolidated measure of social well-being of a child.

The purpose of the work was to study changes in adolescents' reaction to frustration under directed influence by means of art therapy, and the expected result was the development of constructive reactions to frustration.

The general hypothesis was that special means and methods of art therapy (the author's art therapy program that includes engagement with pictorial and natural materials with the elements of music therapy) contribute to development of constructive reactions of adolescents to frustration, with positive implications for directedness, type, and intensity of the reaction.

Objectives of the study: 1. Explore the peculiarities and specifics of reactions to frustration of adolescent schoolchildren from socially advantaged and disadvantaged groups, and find indications of constructive and non-constructive reactions based on age characteristics. 2. Define main psychological factors that determine development of constructive reactions of adolescents to frustration (under directed influence by means of art therapy) and, based on them, build a theoretical model of constructive reaction development for adolescents. 3. Develop and test a special art therapy program (that includes author's methodology "Floristic collage") aimed at development of constructive ways of emotional reaction to frustration by directed formation of positive mental states and reactions. Describe the nature of influence of the developed program on adolescents' reactions from socially advantaged and disadvantaged groups. The research was conducted at three schools in Sergiev Posad, Moscow region: Secondary School No 22, Evening School, and Gymnasium School No 5. The total number in the selected groups was 203 pupils from $8^{\text {th }}$ and $9^{\text {th }}$ grades. The adolescents from socially disadvantaged group included the most vulnerable category of children being under risk due to poverty, special educational needs, family problems and unlawful behavior. The research took five years.

\section{Experiment}

The experimental study consisted of 4 stages: 1) ascertaining experiment - diagnostic study; 2) check phase - mathematical analysis of the findings, composition of control and experimental groups, confirmation of diagnostic value of sample groups that enter into the modeling experiment; 3) modeling experiment - development and testing of a special program aimed at positive changes in adolescents' reactions to frustration; 4) interpretation stage (analysis of the results of the modeling experiment) - second diagnostic snapshot of control and experimental groups, interpretation of data, and drawing conclusions. Each stage has its own objectives, goals, hypothesizes, and applied methods. The general hypothesis of the ascertaining experiment was based on the assumption that most adolescents from upper secondary school tend to have non-constructive reactions to frustration - both 
in socially advantaged and disadvantaged groups. In ascertaining experiment, 203 adolescents took 8 part (110 - from a socially advantaged group, and 93 - from a socially disadvantaged group). The methods used were Rosenzweig test for studying reactions to frustration, verbal frustration test by L. Sobchik, methods of mathematical statistics (One-way analysis of variance, Student's $t$-test).

The analysis of the ascertaining experiment results showed that in both social groups non- constructive reactions prevailed (combination of the dominant type and direction of reactions is characterized by explicit aggressive behavior - active denial of one's guilt and accusations of others). However, the degree of frustration differs significantly in two groups (by significance level $p<0.01$ according to Student's $t$-test). Frustration level of the adolescents from the socially advantaged group is close to norm, while that of adolescents from the socially disadvantaged group is elevated.

At the second stage of the experiment, two groups were formed - control group and experimental group (separately within each social sampling) - to trace the forming effects of the developed program. During the check phase, a lack of relevant differences between socially advantaged and disadvantaged groups was detected, and this confirmed the diagnostic value of the data obtained at the forming stage of the experiment.

At the third stage of the study, the modeling experiment was conducted: a program aimed at making positive changes in emotional reactions of adolescents from the experimental groups was developed and implemented. The forming experiment was based on the development model of constructive reactions of adolescents to frustration by means of art therapy (Fig. 2). Theoretical model laid the ground for the development of a special program, implemented in the experimental groups, that implies active influence on psychological characteristics being studied (type, direction, and intensity of reactions).

In the modeling experiment 129 adolescents of $13-15$ years old participated. They were divided into 4 groups:

- Experimental group of adolescents from socially advantaged group - 37

- Control group of adolescents from socially advantaged group - 38

- Experimental group of adolescents from socially disadvantaged group - 27

- Control group of adolescents from socially disadvantaged group - 27

The purpose of the experiment was to examine how the developed program influences adolescents' reactions to frustration. The hypothesis of the experiment was based on the assumption that the author's special art therapy program has positive influence on direction, type and intensity of constructive reactions of adolescent schoolchildren to frustration.

At the fourth stage of the experiment, the second diagnostic snapshot of experimental and control groups was made using methods from the first analysis. 


\section{Program}

Program on "Development of constructive reactions to frustration among adolescents by means of art therapy" consists of 3 sections (14 sessions to be held at school): 1) Introduction section (4 sessions), 2) Main section (4 sessions), 3) Consolidation section (6 sessions). The realization takes 1-1.5 hours a week for each group.

Program objectives: 1) development of positive mental states and imbedding them in adolescents' reactions and in traits being developed; 2) development of constructive means of self-expression among adolescents; 3 ) development of constructive reactions to frustration.

Program tasks: 1. Acquisition of self-regulation skills. 2. Learning constructive ways of self- expression. 3. Realization of adolescent need for self-expression (in constructive forms). 4. Prevention of elevated frustration.

Main phases of the program: 1 . Actualization of positive (resource) mental states, relevant needs and motivated goals. 2. Integration of positive mental states of a personality and a group in the process of new state pattern formation. Realization of the need for selfexpression. 3. Restructuring and recognition of new reactions. Preservation of positive tendency toward development of constructive reactions to frustration.

In the context of development of constructive reactions to frustration mechanisms of psychological protection as means of personality adaptation play a major role. Frustration sets in motion a whole set of defense reactions, and one of them takes a central place. The most constructive way of adaptation contributing to personality development would be conscious, active reaction aimed at resolving frustrating situation. Development of constructive reactions is driven by: emotional state regulation; selection of productive reaction strategies; resilience to difficult situations; personality traits according to individual types; differences in nervous system; specifics of needs and motivations sphere; mechanisms of volitional regulation (Kuzmina \& Yakunin, 1997; Levitov, 1967; Rosenzweig, 1944, 1945; Tarabrina, 1984). Special methods of art therapy may become means of self-regulation development in the process of directed formation of positive mental states and reactions to frustration.

Directed actualization of positive (resource) mental states among adolescents has become an important part of the art therapy process in the developed program. During exercises, negative psychological defense is withdrawn, and the hidden state becomes open (reacting to emotions - desire to speak out). The process of recognition of one's state pattern is actualized on different levels (conscious, unconscious) thanks to feedback, positive impression of one's potential is built, and constructive ways of self-expression are developed. During exercises, the following processes take place: transformation of negative states into positive (resource) ones, search for solution and decision- making in the art product. Positive mental states are integrated into the process of formation of sustainable psychological traits. Need for self-expression is fulfilled which contributes to preventing frustration and developing constructive reactions to frustration among adolescents. 
The program was designed to give adolescents an opportunity to overcome created barriers during the art therapy process, and this was one of the specific tasks of the experiment. The aim of situations simulated by the psychologist was to frustrate the emotional sphere of adolescents. During exercises, emotional reactions underwent certain changes: 1) initial reaction to the exercise; 2) search for solution and making decision; 3) completion of the exercise overcoming barriers during constructive art process; 4) unconscious fixation of the reaction in the process of creative self-expression (catharsis of the reaction and verbal response). In offered exercises, frustration was triggered by the following factors: unusual nature of the tasks (work with natural and pictorial materials, special background music, tactile contact with natural material, sparking off a range of emotions unknown to adolescents before). Targeted usage of music therapy elements was intended to provoke catharsis and counter- catharsis states while experiencing ("perezhivanie") both positive and negative emotions (overcoming frustration). The main purpose of using music therapy elements in the program was linked with the fact that dynamics of music determines dynamics of states.

1st section of the program. During the first phase of the work, demonstrated dynamics is seen in actualization and growth of positive states through their multiple repetition while doing exercises. After repeatedly overcoming barriers in art therapy exercises, positive (constructive) states were noted: satisfaction, interest, joy, success, etc., meeting the objective of the preparation phase and reflected in willingness and desire to explore oneself more deeply. The end purpose of this phase was to response to those emotional states, remove psychological barriers, become able to go deeper in understanding oneself, one's psychological problems and specifics, boost motivation to further participation in psychological correction.

2nd section of the program. Tendency to constructive reaction to frustration. In the second stage, mental states of the participants (directedness, intensity and other characteristics of emotions) became common for the whole group as they are simulated in the same situation for all members of the group (exercises are designed to be done in a group accompanied by special music). The productivity of exercises is ensured by the consolidation of the group at the first stage. By the end of the second section of the program we saw communication readiness, decisiveness to face challenge/overcome barrier and materialization in the artistic image, signs of fixation positive emotions through verbal feedback. A new group mental state is formed: the adolescents become emotionally open and get more confident and ready to move to the third stage.

3rd section of the program. Fixation of positive mental states and transformation of positive (constructive) states into the process of formation of constructive reactions. The main strategy was to repeat positive mental states in each new exercise, moving from one state to another, and, as a result, integrate positive states into the process of formation of stable traits. Specific feature of states appearing in response at the third stage is their common nature for the whole group. Experiencing satisfaction, success, inspiration, boost at both group and individual level, creative work and co-work with verbalization and fixation of new positive states and feelings. 
Author's art therapy methodology "Floristic collage" (2nd and 3rd sections of the program, 10 sessions) was used in exercises with natural materials to form positive mental states and reactions among adolescents, deepening art therapy effect and, in addition, activating sensory systems: visual, audial, and kinesthetic. The methodology uses selected psychological factors that determine positive change in reaction to frustration and bases on the leading factor: integration of positive mental states into the process of formation of personality traits through deep art therapy influence (activation of sensory systems) (Yangicher, 2009). The more perceptive channels are engaged in the process of influencing on mental states of adolescents, the more effective is the transition from mental states to the process of formation of stable traits. Thus, along with other art therapy means (drawing activities, music therapy) our experimental study was focused on using natural materials that influence emotional sphere of an adolescent.

Sessions with natural materials are aimed at creating positive mental states such as calm, confidence, satisfaction, interest, joy, inspiration, etc. that, being repeated in the following sessions, are reflected in the adolescents' art works. We see floristic material as resource-intensive for art therapy in respect of adolescents. Foreign researchers point out that the growing techno-genetics influence deprives children of communication with nature, discourages personal contacts and leads to social closure. They stress that in this context, art therapy has the most effect in problem solving, which opens the door wide for the method in the future (Klorer, 2009). Consistent contact with different art materials invoking kinesthetic sensations and perceptive affects, helps to work on emotionally relevant situations and traumatic experience at sensory level (Malchiodi, 2003). Contact with natural materials lays the ground for producing the above effect, as it is inevitably associated with learning the texture, form, color, smell, etc. and thus activating visual, audial, and kinesthetic channels.

In order to build an experience, each exercise provokes frustration caused by unusual requirements, difficult creativity tasks to be completed, the need to find solution on one's own. During exercises, creative self-expression is activated, and new experience in constructive overcoming of model barriers is obtained. By presenting art products to the group, verbalizing the experience received in the form of states, analyzing key moments of work, the adolescent repeats the positive part of the process at the end of the session fixing new constructive reaction to frustration in his/her experience. Therefore, the following factors contribute to development of constructive reactions: solving an unusual problem at the emotional level, activation of leading sensory channels and tactile sensations; the factor of "living through" the artistic image, which teaches how to think outside the box and destroys stereotypes in reactions; the group factor (adolescents watch, listen and cooperate). All sessions are accompanied by instructions, verbal feedback, discussions with other participants. 


\subsection{Session blocks (as per the main sections of the program).}

Objectives of the 1st section: establish personal contacts in the group, consolidation of the group, build trust relationships, motivate the group to complete tasks, alleviate emotional tension (relaxation); relieve from negative emotions and states; realize the experienced emotions and express them in the artistic process.

1st session block.

Session 1. Drawing in a circle. Group drawing in turns (consolidation of the group, realization and verbalization of relevant emotions).

Session 2. Drawing of figures (continuous blind drawing of geometric figures). Alleviation of emotional tension (relaxation); relief from negative emotions, verbal self-assessment of the experienced states.

Session 3. "Language of sound and color" (including elements of music therapy). Expression of emotional state induced by music in drawing; simulation of frustration (unusual nature of tasks): to picture psychological and emotional states (fear, anxiety, joy, sadness, calm, happiness, etc.) using art means.

Session 4. "Me real, and me ideal". Picturing one's inner self: real and ideal, comparison of images. Working on positive and negative mental states, personality traits. Overcoming internal conflicts, realizing them and finding solution in art products. Materials used.

In exercises of the 1st section adolescents use sheets of paper and colored pencils (session 3 is accompanied by compositions of Mussorgsky, Schubert, Mozart, Vivaldi, Tchaikovsky).

Objectives of the 2nd section: integrate positive mental states of an individual and a group into the process of formation of a new image; activate tactile sensations and sensory perception during targeted engagement with texture of the materials used in order to speed up the integration process; realize the need for self-expression in art products; reflect realized feelings in works with natural materials. Materials used in the 2nd and $3 r d$ session blocks. Adolescents use floristic material of different texture (leaves and bark, spruce branches, moss, feathers, seashells, small stones, dog-rose branches, prickles, petals, chestnuts, etc.). Cardboard boxes serve as a base for collages. In the 2nd block floristic material may be glued to the base; in the 3rd block the usage of glue is not recommended what is explained by specific objectives of the methodology. Session 9 is conducted under the accompaniment of nature sounds: wind, rain, storm, heat, summer morning, birds in the wood, etc. (at the discretion of the group supervisor). Session 10 uses compositions "The Seasons: Autumn Song" by Pyotr Tchaikovsky and "The Four Seasons: Winter" by Antonio Vivaldi.

2nd session block. 
Session 5. Working with collages: "Rhythm". Introduction to the technique and art means of a floristic collage (texture, form, line, spot, silhouette, color, contrast, rhythm, integrity, harmony, artistic image). Reflection of feelings and emotional states in the created image using art means.

Session 6. Floristic collage in cool colors "Early spring".

Session 7. Floristic collage in warm colors "Leaf fall". Experience emotions and reflect them in the created artistic image using given colors. Directed formation of positive psychological and emotional states. Control of one's state using given art means (color, contrast, temperature of the color). Restructuring of the emotional reaction to the set task (overcoming the barrier: transition from a "difficult" (for adolescents without artistic skills) task to a positive solution found in the art product - catharsis of the esthetic reaction). Acquisition of self-regulation skills.

Session 8. Floristic collage "Home nature". Realization of one's emotional state and its expression in the created image. Realization of relevant feelings in the process of verbalization (by each participant as well as by the whole group). Directed formation of positive psychological and emotional states of the whole group. Integration of resource states into the process of formation of a new image.

Objectives of the 3rd section: restructuring and realization of a new reaction; fixation of the positive tendency to the development of constructive reactions to frustration; acquisition of self-regulation and self-expression skills in challenging situations; prevention of elevated frustration among adolescents.

3rd session block.

Session 9. Floristic collage "Language of nature sounds".

Session 10. Floristic collage "The seasons". Creation of an associative image of nature. Expression of the emotional state triggered by nature sounds and compositions in the created images. Formation of a new mental state at different levels (conscious and unconscious). Expression of the new image in visual, audial, tactile form; realization of a comprehensive response after influencing a range of sensory channels. Realization of the new state image and its verbalization. Easing and prevention of frustration in the course of directed formation of mental states (consecutive playing of nature sounds and compositions ranging from alarming, exciting to calming). Prevention and easing of anxiety. Finding response to aggressive reactions in constructive form. Relief from negative states. Relaxation.

Session 11. Floristic collage "My emotions: experience, realize and express". Development of emotional regulation. Directed formation of positive states by means of specific arrangement of exercises (picture a negative state you want to be relieved from; change the state image into a more positive and desirable one with the help of art means). Alleviation of inner tension by transferring emotions into the created image. Formation of positive 
emotional experience and realization of one's state. Restructuring and fixation of positive emotional reaction to frustrating exercise (verbalization).

Session 12. Floristic collage of a "A person's character". Directed formation of positive mental states, experiencing and realization of social emotions and feelings during tailored exercises: 1) reflection of a personality trait of an adolescent in the artistic image (at one's discretion); 2) change of the created image in the course of group work; 3) creation of integral "ideal" character by the group (lay out the common collage on the floor, replace negative personality traits with positive, exchanging materials in cardboard boxes and moving them). Integration of positive mental states into the process of formation of a new mental state image of the individual and the group. Acquisition of self-regulation skills and learning constructive ways of self- expression.

Session 13. Floristic collage "Me real, and me ideal". Constructive overcoming of difficulties while creating artistic images (determined by the given sequence). Accepting emotions as relevant. Formation of a positive attitude towards one's inner feelings. Accepting oneself. Realization of all aspects of one's mental state. Response to emotions related to the perception of oneself. Changing the mental state to a positive one. Creation of ideal desirable proportions in the image. Realization and fixation of resource mental state based on "visceral information" received through verbal feedback. Directed formation of positive (resource) states of an individual and a group.

Session 14. Floristic collage "Me in the group". Realization of one's role in the group. Accepting oneself and others as equal partners from the tolerance point of view. Reflection of individual needs and relations with other people. Boosting self-confidence, realization of the need for self-expression (in constructive form).

\section{Data Analysis}

After the forming stage (upon implementation of the program in experimental groups) significant differences between sample groups (control and experimental groups) were recorded in a number of characteristics. The data analysis showed that the most positive dynamics was seen in directions of reactions Rosenzweig (1945), while types of reactions remained almost unchanged. It was found that dynamics of reaction characteristics in experimental groups (in different sample groups) is the same: there were positive changes in directions and intensity of reactions. At the same time, in both control groups adolescents' reactions to frustration have stable manifestation forms in the absence of special influence (Yangicher, 2008, 2009, 2010).

The qualitative data analysis that included: examination of art products, monitoring of interim dynamics at session level, description of group and individual dynamics of changes in adolescents' reactions based on observations and video recordings, drawing up observation protocols, analysis of brief psychological history of each participant - showed 
that during art therapy process positive changes in emotional states of adolescents in the experimental groups were recorded at each session.

At the beginning of session, they experienced negative mental states such as tension, aggressiveness, apathy, restraint, anxiety, confusion, fright, fear, offence, shame, anger, hostility, hate, anguish, while at the end of sessions they noted such positive states as calm, joy, enjoyment, excitement, love, gratitude, interest, happiness, etc. Adolescents described their emotions both orally during verbalization practices in classes and in writing filling special "emotion forms" where they noted states experienced at the beginning and at the end of sessions. Below are examples of dynamics of constructive reactions of adolescents from socially advantaged and disadvantaged groups (extracts from protocols of observation and video recordings).

\subsection{Example of step-by-step dynamics of constructive reaction of an adolescent from socially advantaged group}

Kostya, 15 years old, pupil of the 9th grade. The boy is from a two-parent, well-to-do family (second child, has an elder sister). In good health, likes sports, interested in machines. School results are medium. Non-committed to public orders, but hard- working, helps with household chores. He has many friends in his age group. Timid, respectful towards elders. After school, he wants to become mechanic. He is emotionally stable, capable of constructive dialogue with his peers and teachers. During the forming experiment, the dynamics of psychological and emotional states of the adolescent was monitored at main stages of the art therapy program. The analysis of one session reveals a number of interim mental states. 1. Task is set; confusion, realization of the challenge, passive protest. Kostya: "I don't understant how to do that". 2. Tension, anxiety, search for solution. 3. Search for solution, attempt to get away from the problem; tendency towards creation of a new state image. Kostya: "This is good and bad mood" (picture: crossed lines, green band and the sun). 4. Overcoming frustration (tendency towards changing and replacing negative states and reactions with positive ones). 5. Exit from the state of frustration - new state image creation; realization of the experienced states (verbalization); catharsis of the esthetic reaction; self-expression in the art product. Restructuring of the reaction. Kostya: "This is a beautiful green meadow... I like it". 6. Fixation of the new positive state in the reaction (feedback in the group). Comments of the group participants: "he wanted to say that he wants to be more confident", "he wants more joy and light in his life, that's why such bright colors", "the square is crossed, seems that there was some anxiety inside, something kept him from expressing himself. . . and even the sun in the corner is pale... " - Kostya takes the yellow pencil and turns up saturation of the sun. The group leader: "Do you think, the guys are right?". Kostya: "Yes, they are right" - and continues painting with a smile. 


\subsection{Example of step-by-step dynamics of constructive reaction of an adolescent from socially disadvantaged group}

Pasha, 14 years old, pupil of the 8th grade. The boy is from a one-parent family (parents are in divorce), has a younger sister. According to the teachers, Pasha is characterized by hyperactivity, excitability, emotional expansiveness, in the moments of excitement his pain threshold reduces (he can extinguish a cigarette on his hand). Pasha attended art therapy sessions with pleasure, was active. During exercises demonstrated impulsive reactions. By the end of the art therapy program, significant changes in the intensity of frustration were detected. Positive dynamics was seen at the single session level, but due to time deficiency of the program, it was not fixed in stable manifestation forms. Dynamics of reactions to frustration at the level of a single session: 1. Task is set. Confusion, frustration. 2. Selection of art material to complete the task. 3. Search for solution (group interaction). 4. The process of "constructive creativity", expressive description of the created state image, self-expression in the art product. Verbalization: Pasha: "I' $m$ volatile: sometimes I' $m$ kind, sometimes... (throws up his hands)", "there are roses, they also sometimes make me good... and this is prickle, bad prickle!" The group leader: "And what part is bigger?" Pasha: "The good one... roses, feathers". The group leader: "Do you have something else?" Pasha: "Love...for people, love... here while I'm kind". 5. Response to the experienced emotional states in reactions (verbalization). Catharsis of the reaction, relief from negative states, decrease of the elevated reaction impulsiveness.

Findings showed that the psycho-correction of adolescents' reactions to frustration (from both socially advantaged and disadvantaged groups) was possible by intervention directed at the regulation of the mental states where the emotional reaction took place, through targeted art-based approaches (specifically art therapy methods).

The course of action directed at the mental states led to the modification, substitution and retention of negative to positive mental states, which resulted in the restructuring of the emotional response and led to long term changes in the stereotypical reaction.

\section{Conclusion}

There is a controversy over understanding of problems of psychological and emotional regulation and the concept of frustration phenomenon between foreign and Russian psychologists. In Russian psychological school, this phenomenon is predominantly studied as a category of mental states. This stance, in our view, provides an opportunity to consider correctional influence on non-constructive reactions of adolescents to frustration. In this context, psychological correction process implies targeted influence with special means on the process of formation of new positive mental states integrating into stable personality traits (in the course of changing and replacing negative states with positive ones, and their fixation, which leads to the restructuring of the reaction and change in the established stereotype). The key to this psychological correction process is the category of mental states that becomes interim and helps to integrate and fix positive experience (during special in- 
fluence) in new stable personality traits. As instruments of psychological influence can be considered special means of art therapy methods that contribute to directed formation of positive mental states and reactions in adolescence and facilitate integration of positive (resource) metal states into the process of formation of a new reaction, as well as realize the adolescents' need for self-expression (in constructive forms) preventing and reducing elevated frustration

Longer-term forming influences with the aim to fix positive mental states in stable personality traits and to change established stereotypic reactions are seen as prospective areas for further studies. Special prolonged influence on adolescents' mental states using art therapy means opens the prospect of formation of constructive behavioral reactions.

\section{References}

Adam, J. (1998). Visceral perception: understanding internal cognition. New York: Springer Science \& Business Media.

Barker, R. G., Dembo, T., \& Lewin, K. (1943). Frustration and regression: An experiment with young children. University of Iowa Studies in Child Welfare, 18(1).

Bozhovic, L. I. (1968). Lichnost'i ee formirovanie v detskom vozraste: psihologiceskoe issledovanie (personality and its development in childhood: A psychological investigation). Akad.ped. nauk SSSR. [Academy of Educational Sciences of USSR].

Dalley, T., Rifkind, G., \& Terry, K. (1993). Three voices of art therapy: Image, client, therapist. New York: Routledge.

Dikaya, L. G., \& Semikin, V. V. (1984). Problem of control of human operators state. Moscow: Mezhdunarodnaya Kniga.

Dollard, J., Miller, N. E., Doob, L. W., Mowrer, O. H., \& Sears, R. R. (1939). Frustration and aggression. New Haven: Yale University Press.

Essex, M., Frostig, K., \& Hertz, J. (1996). In the service of children: Art and expressive therapies in public schools. Art Therapy, 13(3), 181-190.

Freud, S. (1923). Certain neurotic mechanisms in jealousy, paranoia and homosexuality. The International Journal of Psycho-Analysis, 4, 1.

Klorer, P. G. (2009). The effects of technological overload on children: An art therapist's perspective. Art Therapy, 26(2), 80-82.

Kon, I. S. (1989). Psikhologiia rannei iunosti [The psychology of the early youth]. Moscow: Prosveshchenie.

Kramer, E. (1975). Art as therapy with children. American Journal of Art Therapy.

Krech, D., \& Livson, N. (1969). Elements of psychology. New York: AA Knopf Inc.

Kulikov, L. V. (1997). Psikhologiya nastroyeniya (Psychology of mood). St. Petersburg: Peter.

Kuzmina, E. I., \& Yakunin, V. A. (1997). Study of determinants of freedom and of unfreedom from frustration. The Issues Relevant to Psychology(24), 86-94.

Leont'ev, A. (1971). Potrebnosti, motivy i jemocii (Vol. 187). Moscow: Izd-vo Mosk. un-ta.

Levitov, N. D. (1964a). Detskaja i pedagogicheskaja psihologija [childhood and pedagogical psychology]. Moscow: Prosveshhenie.

Levitov, N. D. (1964b). O psihicheskih sostojanijah cheloveka [about the mental states of a person]. 
Moscow: Prosveshhenie.

Levitov, N. D. (1967). Frustracija kak odin iz vidov psihicheskih sostojanij [frustration as one of mental state types]. Voprosy psihologii [The Issues Relevant to Psychology](6), 118-129.

Levitov, N. D. (1969). The psychology of character. Moscow: Prosveshhenie.

Lukin, S. E. (1993). Frustration test of S. Rosenzweig. St-Petersburg: Imaton.

Malchiodi, S. (2003). Handbook of art therapy. New York: Guilford Press.

Moriya, D. (2000). Art therapy in schools. Ramat Hashron: Turbo.

Naumburg, M. (1973). Studies of the free expression of behavior disturbed children as a means of diagnosis and therapy. New York: AA Knopf Inc.

Nekrasova, J. B. (1994). O psihicheskih sostojanijah, ih diagnostike, upravlenii i napravlennom formirovanii (v processe socioreabilitacii zaikajushhihsja) [about mental states, their diagnostics, control and directed formation (in the process of sociorehabilitation of stutterers]. Voprosy psihologii [The Issues Relevant to Psychology](6), 37-41.

Prihozhan, A. M. (2000). Trevozhnost' u detej i podrostkov: psihologicheskaja priroda i vozrastnaja dinamika [Anxiety among children and adolescents: psychological nature and age dynamics]. Voronezh: Izd-voNPOModjek.

Prohorov, A. O. (1990). Samoreguljacija psihicheskih sostojanij v uchebnoj i pedagogicheskoj dejatel'nosti [Mental states self-regulation in learning and teaching activity]. Voprosy psihologii [The Issues Relevant to Psychology](5), 156-161.

Prohorov, A. O. (1994). Integrirujushhaja funkcija psihicheskih sostojanij [An integrating function of mental states]. Psihologicheskij zhurnal [Psychological Journal], 15(3), 136145.

Prohorov, A. O. (2002). Psihologija psihicheskih sostojanij: Sb. statej [Psychology of mental states: Coll. articles] (Vol. 4). Kazan: Izd-vo Centr innovacionnyh tehnologij.

Prokhorova, V. N. (1996). Russkaya terminologiya (leksiko-semanticheskoe obrazovanie)[Russian terminology (lexical-semantic education)]. Moscow: Filologicheskiy fakul'tet Publ.

Rean, A. A. (1999). Social pedagogical psychology. St-Petersburg: Peter.

Riley, S. (2004). The creative mind. Art Therapy, 21(4), 184-190.

Rosenzweig, S. (1944). An outline of frustration theory. In J. Hunt (Ed.), Mcv, personality and behavior disorders (p. 379-388). New York: Ronald Press.

Rosenzweig, S. (1945). The picture-association method and its application in a study of reactions to frustration. Journal of personality, 14(1), 3-23.

Rosenzweig, S. (1976). Aggressive behavior and the rosenzweig picture-frustration (P-F) study. Journal of Clinical psychology, 32(4), 885-891.

Smirnov, S. D. (1981). The world of images and the image of the world. Soviet Psychology, 20(2), 3-27.

Sosnovikova, Y. E. (1972). Age aspect of mental states. The Issues Relevant to Psychology(2), 141-144.

Steele, W., \& Raider, M. (2001). Structured sensory intervention for traumatized children, adolescents, and parents: Strategies to alleviate trauma (Vol. 1). New York: Edwin Mellen Press.

Tarabrina, N. V. (1984). Eksperimental'no-psikhologicheskaia metodika izucheniia frustratsionnykh reaktsii: Metodicheskie rekomendatsii [experimental psychological methods of studying the reactions of frustration: Guidelines]. Leningrad: Izd-vo NIPI im. VM Bekhtereva. 
Vasiljuk, F. E. (1984). Psihologija perezhivanija: Analiz preodolenija kriticheskih situacij [Life experience: Analysis of overcoming critical situations]. Moscow: Mosk. un-t publ.

Vasiljuk, F. E. (1991). The psychology of experiencing: The resolution of life's critical situations. Hemel Hempstead, UK: Harvester Wheatsheaf.

Vasilyuk, F. E. (1984). Psychology experiences. Analysis of overcoming critical situations. Moscow: Izd-vo Mosk. University Press.

Vygotsky, L. S. (1966). Development of the higher mental functions. Psychol. research in the USSR, 1, 11-46.

Vygotsky, L. S. (1972). The psychology of art. Moscow: Art.

Vygotsky, L. S. (1991). Imagination and creativity in the adolescent. Soviet Psychology, 29(1), 73-88.

Vygotsky, L. S. (1998). The problem of age. In R. W. Rieber \& A. S. Carton (Eds.), The collected works of L. S. Vygotsky (Vol. 5, pp. 187-205). New York: Plenum Press.

Yangicher, E. V. (2008). Razvitie tvorcheskih sposobnostej i korrekcija psihologicheskih narushenij $\mathrm{u}$ detej sirot $\mathrm{v}$ processe raboty s prirodnymi materialami [Development of artistic skills and correction of psychological impairments among orphans in the process of work with naturally-appearing materials]. In Materialy mezhdunarodnoj nauchno-prakticheskoj konferencii «iii levitovskie chtenija» 21 apr.2008 [materials of world science-practical conference «third levitov's readings» 2008 april 21] (p. 239-242). Moscow: Izd-vo MGOU.

Yangicher, E. V. (2009). Art therapy in development of positive emotional reactions of adolescents. Art and Education, 6, 149-161.

Yangicher, E. V. (2010). Razvitie konstruktivnyh frustracionnyh reakcij podrostkov sredstvami art- terapii (Unpublished doctoral dissertation). PhD in psychology, Moscow. 